\title{
COVID-19 Vaccination - A Cross Sectional Survey on Attitude and Belief of Nurses
}

\author{
Sonali Tarachand Jadhav ${ }^{1}$, Kusum Gurung ${ }^{2}$ \\ ${ }^{1}$ Department of Medical Surgical Nursing, ${ }^{2}$ Department of Psychiatric Nursing, \\ Ramaiah Institute of Nursing Education \& Research, Bengaluru, India \\ Corresponding Author: Kusum Gurung
}

DOI: https://doi.org/10.52403/ijshr.20220123

\begin{abstract}
Background: Nurses are the largest part of health care workers involved in direct covid care. This study was intended to identify attitude and beliefs of nurses and nursing students towards covid vaccination immediately after the launch of vaccination drive for health care workers.
\end{abstract}

Materials and Methods: The study used a cross sectional survey among nurses and nursing students, studying/working in various institutions in Karnataka recruited through snowball sampling. Google survey questionnaire was sent through social media application, WhatsApp.

Results: Twenty per cent of the study participants had already received the first dose of vaccine. Among those who had not received the vaccine, majority of nurses were afraid of the side effects of the vaccine $(35 \%)$ and $24 \%$ wanted to wait and watch. A large number of study participants $(38 \%)$ expressed that they were 'not sure' of the protective effect of vaccine and $10 \%$ believed that vaccine was not safe. Only $4 \%$ of the participants said that they would never take the vaccine. Involvement in direct care of patients' with covid infection was strongly associated with willingness to take the vaccine $(0.001, \mathrm{P}<0.05)$.

Conclusions: The results of the study indicate that there is a need for robust information, education and counselling measures that need to be adopted focusing on nurses as frontline health care workers to convince them to take covid-19 vaccine.

Keywords: [COVID-19 vaccine, nurses, attitude, belief]

\section{INTRODUCTION}

In March 2020, the World Health Organization (WHO) declared the COVID19 outbreak a pandemic. $^{1}$ From a few thousands confirmed COVID-19 cases in January 2020, cases continue to grow globally. As of $2^{\text {nd }}$ July 2021, there have been 18,23,19,261 confirmed cases of COVID-19, including 39,54,324 deaths, reported to WHO. In India, 3,04,58,251 confirmed cases of COVID-19, including $4,00,312$ deaths have been reported as of $2^{\text {nd }}$ July $2021 .^{2}$ Many health care workers have been infected with COVID-19 and have lost their lives worldwide during the pandemic. A systematic review on Infection and mortality of healthcare workers worldwide from COVID-19 by Bandyopadhyay $\mathrm{S}$ et al, reveals that $38.6 \%$ (10706) nurses were affected by COVID-19 infection and $25.3 \%$ (259) deaths were reported among nurses. ${ }^{3}$ In many countries, nurses are the largest health worker group affected with COVID19 infection. As of $31^{\text {st }}$ January 2021, the cumulative number of reported COVID-19 deaths in nurses in 59 countries as per International Council of Nurses is $2,710{ }^{4}$ As per the data available from Trained Nurses Association, on $31^{\text {st }}$ May 2021, the cumulative number of reported COVID-19 infections among nurses were 517 with 126 deaths. $^{5}$

The Government of India launched COVID-19 vaccination drive on $16^{\text {th }}$ January 2021 and the first beneficiaries were healthcare workers ( $\mathrm{HCW}$ ) across the 
Nation as healthcare workers are part of the frontline in the fight against the pandemic. ${ }^{1}$ Although the Government of India had announced to provide COVID-19 vaccine to Health care workers free of charge, many Health care workers showed unwillingness to take the vaccine and many were still hesitant to take the vaccine.

In 2015, the World Health Organization (WHO) Strategic Advisory Group of Experts on Immunization defined vaccine hesitancy as a 'delay in acceptance or refusal of vaccination despite availability of vaccination services. Concern about vaccine hesitancy is growing worldwide and WHO identified it as one of the top ten global health threats in $2019 .{ }^{6}$ According to WHO National Health Workforce Accounts (NHWA) data Portal, in India, nurses have $47 \%$ of share within health workforce and the vaccine is yet to find acceptance among a part of healthcare workers including nurses. $^{7}$

This study was intended to identify attitude and beliefs towards covid vaccination among nurses and nursing students immediately after the launch of vaccination drive for health care workers.

\section{MATERIALS \& METHODS}

The study used a cross sectional survey to assess attitudes and beliefs of nurses towards covid vaccine. The survey was conducted from $18^{\text {th }}$ January 2021 to $14^{\text {th }}$ March, 2021. A Google survey questionnaire was created after reviewing relevant literature and consultation with subject experts. The questionnaire consisted of a total of 14 items. The initial nine items were intended to elicit socio-demographic information of the participant. The rest of the five items were focused on understanding attitudes and beliefs and willingness/hesitancy of participants for getting vaccinated. The last item sought information about side effects experienced by subjects who had already received their first dose of vaccine. The content validity of the tool was established by giving it to seven experts which included four senior nurses and three doctors. The tool was assessed for its internal consistency using split half method and was found reliable $(r=$ $0.9, \mathrm{P}<0.05)$. The ethical clearance for the study was obtained from the institution's ethical review board.

The participants for this study included nurses and nursing students, studying/working in various institutions in Karnataka. The Google survey questionnaire was sent to 1500 subjects through social media application, Whatsapp. The snowball sampling was used to recruit participants for this study. The subjects were given brief information about purpose of the survey at the beginning of the Google form and were required to indicate their consent for taking up the survey before proceeding to answer it. A total of 904 participants responded to the survey. Among the survey forms received from subjects' four forms were found incomplete and were hence excluded for analysis.

\section{RESULT}

Most participants in this study were female nurses (79\%), aged between 18-24 years $(73 \%)$ with majority having General Nursing and Midwifery (41\%) and B.Sc. Nursing (42\%) being their educational qualification. Majority worked in private hospitals (89\%) as interns $(69.8 \%)$ and staff nurses $(14.2 \%)$ with $23 \%$ involved in direct care of covid positive patients. Among the study participants $14 \%$ reported that they had been infected with covid and $7 \%$ reported that at least one of their family members was infected with covid infection.

With regards to beliefs of nurses regarding potential protective effect of vaccine, $53 \%$ believed that the vaccine will protect them from the severe covid infection and only $9 \%$ felt that the vaccine is not capable of providing any protection. However, a large number of study participants $(38 \%)$ expressed that they were 'not sure' of the protective effect of vaccine. Nearly half of the participants $(52 \%)$ felt that the vaccine is safe and $38 \%$ participants were not sure of/neutral regarding the safety 

nurses

aspects related to covid 19 vaccine. Only 10 $\%$ believed that it may not be safe to take this vaccine.

Only $20 \%$ of the study participants had already received the first dose of vaccine and another $28 \%$ were willing to take it immediately. A large number of participants $(26 \%)$ wanted to wait and watch for some more time to make their decision about taking the vaccine. Only 4\% (32) of the participants said that they would never take the vaccine and $22 \%$ were not sure about their decision.

Among those who were not willing to take vaccine, majority of nurses said that they were afraid of the side effects of the vaccine $(35 \%)$ and $24 \%$ said that they wanted to wait and watch. The other reasons cited by participants for not willing to take the vaccine are depicted in figure- 1 .

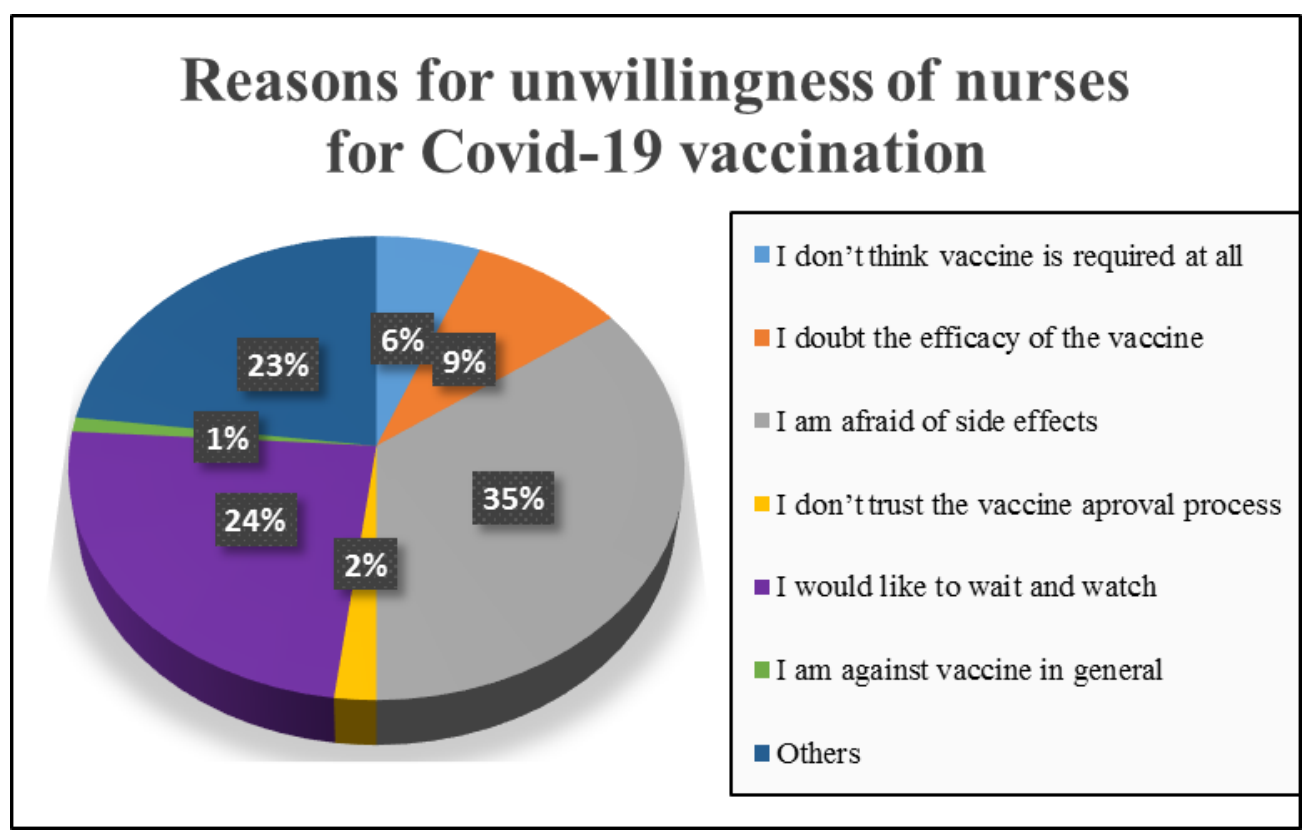

Figure-1: Reasons for unwillingness of nurses for Covid-19 vaccination

Among those who received the first dose of vaccine, pain at Injection site was the most reported side effects (103) followed by fever (83), tiredness/fatigue (65), headache (64), muscle pain (49), joint pain (34), giddiness (18), nausea (10), allergic reaction/rashes (2) and breathing difficulty (1).
The Chi square test was used to find association between the willingness to take covid vaccine and selected sociodemographic variables (Table-1). Involvement in direct care of patients' with covid infection was found to be strongly associated with willingness to take the vaccine.

Table-1: Association between willingness of nurses to take covid vaccine and selected sociodemographic variables

\begin{tabular}{|c|c|c|c|c|c|c|c|}
\hline \multirow{2}{*}{\multicolumn{2}{|c|}{ Demographic variables }} & \multicolumn{3}{|c|}{ Are you taking covid vaccine for yourself? } & \multirow[t]{2}{*}{ Total } & \multirow{2}{*}{$\begin{array}{c}\text { Chi square } \\
\left(\chi^{2}\right)\end{array}$} & \multirow[t]{2}{*}{ P-value } \\
\hline & & Yes & No & I have already taken it & & & \\
\hline \multirow[t]{4}{*}{ Were you diagnosed with Covid? } & \multirow[t]{2}{*}{ Yes } & 40 & 57 & 25 & 122 & \multirow[t]{4}{*}{1.592} & \multirow{4}{*}{$\begin{array}{l}0.451 \\
(\mathrm{NS})\end{array}$} \\
\hline & & $32.8 \%$ & $46.7 \%$ & $20.5 \%$ & $100.0 \%$ & & \\
\hline & \multirow[t]{2}{*}{ No } & 216 & 407 & 155 & 778 & & \\
\hline & & $27.8 \%$ & $52.3 \%$ & $19.9 \%$ & $100.0 \%$ & & \\
\hline \multirow{4}{*}{$\begin{array}{l}\text { Did any of your family member } \\
\text { test positive for COVID-19? }\end{array}$} & \multirow[t]{2}{*}{ Yes } & 15 & 30 & 16 & 61 & \multirow[t]{4}{*}{1.683} & \multirow{4}{*}{$\begin{array}{l}0.431 \\
(\mathrm{NS})\end{array}$} \\
\hline & & $24.6 \%$ & $49.2 \%$ & $26.2 \%$ & $100.0 \%$ & & \\
\hline & \multirow[t]{2}{*}{ No } & 241 & 434 & 164 & 839 & & \\
\hline & & $28.7 \%$ & $51.7 \%$ & $19.5 \%$ & $100.0 \%$ & & \\
\hline \multirow{4}{*}{$\begin{array}{l}\text { Were you involved in direct care } \\
\text { of Covid patients? }\end{array}$} & \multirow[t]{2}{*}{ Yes } & 64 & 83 & 56 & 203 & \multirow[t]{4}{*}{14.206} & \multirow{4}{*}{$\begin{array}{l}0.001 \\
(\mathrm{~S})\end{array}$} \\
\hline & & $31.5 \%$ & $40.9 \%$ & $27.6 \%$ & $100.0 \%$ & & \\
\hline & \multirow[t]{2}{*}{ No } & 192 & 381 & 124 & 697 & & \\
\hline & & $27.5 \%$ & $54.7 \%$ & $17.8 \%$ & $100.0 \%$ & & \\
\hline \multicolumn{2}{|l|}{ Total } & 256 & 464 & 180 & 900 & & \\
\hline
\end{tabular}

Significance at $\mathrm{P}<0.05$ (two tailed), $\mathrm{df}=2$ 


\section{DISCUSSION}

Enrolment for phase III clinical trials for Covishield vaccine by Serum Institute of India (SII) in partnership with Indian Council for Medical Research (ICMR) was completed on $31^{\text {st }}$ October as per the press release by ICMR dated $12^{\text {th }}$ November 2020. The Government of India Authorized SII for emergency use of Covishield vaccine on $6^{\text {th }}$ January 2021. The US trial data showed the vaccine's efficacy of $79 \%$ was achieved when two standard doses were given at an interval of four weeks, while data from UK trials showed an efficacy of $53 \%$ for interval of less than six weeks. ${ }^{8}$ The vaccine was made available at free of cost only for health care workers and frontline workers in the first phase of vaccine launch on $16^{\text {th }}$ January 2021. We commenced our survey among nurses on $18^{\text {th }}$ January 2021 and completed the data collection on $14^{\text {th }}$ March 2021.

The study findings show that a large number of nurses wanted to wait and watch $(26 \%)$ or were not sure of taking the vaccine immediately $(22 \%)$ and $35 \%$ were concerned about the side effects of the vaccine. Safety issues related to vaccine and fear of vaccine side effects emerge to be predominant reasons for vaccine hesitancy among the participants. Several studies report these to be primary reasons of vaccine hesitancy among Health care workers $(\mathrm{HCW}){ }^{9,10}$ The process of development of covid vaccine was very rapid as compared to usual time taken to develop any vaccine. The vaccine was approved only for emergency use and the phase III trial of vaccine was still pending. This probably caused concerns among the nurses to make a decision to be vaccinated. However the acceptability of covid vaccine among nurses is not so different than the acceptability of hepatitis B vaccine which is also an essential vaccine recommended for all healthcare workers. Studies report that acceptability of hepatitis $\mathrm{B}$ vaccine ranges between 25-50 \% among HCW. ${ }^{11,12}$ Perceived low susceptibility to infection, high cost of vaccine and fear of side effects were some of the reported factors leading to non-acceptance of hepatitis B vaccine. ${ }^{11,13}$

The National AEFI (Adverse Event Following Immunization) committee noted that as of 03 April 2021, 75,435,381 vaccine doses had been administered (Covishield68,650,819; Covaxin-6,784,562). Of these, $65,944,106$ were first doses and 9,491,275 were second dose. Since the COVID-19 vaccination drive was initiated, more than 23,000 adverse events were reported through the CO-WIN platform. And these were reported from 684 of the 753 districts of the country. Of these, only 700 cases $(9.3$ cases/million doses administered) were reported to be serious and severe nature. ${ }^{14}$

\section{CONCLUSION}

Nurses being the health care professionals, who are frontline workers, are at the highest risk for acquiring the infection and the vaccine hesitancy among the nurses that was found by the study is certainly a reason to worry. The results of the study indicate that there is a need for robust information, education and counselling measures that need to be adopted focusing on nurses as frontline health care workers to convince them to take covid-19 vaccine.

Acknowledgement: None

Conflict of Interest: None

Source of Funding: None

Ethical Approval: Approved

\section{REFERENCES}

1. Covid-19 vaccines operational guidelines. New Delhi, India: Ministry of health and family welfare, Government of India; 28 Dec, 2020. Available from: https://www.mohfw.gov.in/pdf/COVID19V accineOG111Chapter16.pdf [Last accessed on 2021 June 20]

2. World health organization. WHO Coronavirus (COVID-19) Dashboard. Geneva; 2 July 2021. Available from: https://covid19.who.int/ [Last accessed on 2021 July 02]

3. Bandyopadhyay S, Baticulon RE, Kadhum M, Alser M, Ojuka D,Badereddin Y, 
Kamath A, et al. Infection and mortality of healthcare workers worldwide from COVID-19: a systematic review. BMJ Glob Health. 2020; 5(12):1-11.

4. International Council of Nurses. Geneva: INC; 12 Feb 2021. Available from: https://www.icn.ch/sites/default/files/inlinefiles/IND2021-Factsheet-01-UPDATEDEN.pdf [Last accessed on 2021 July 14].

5. The Trained Nurses' Association of India. Covid tracker for nurses in India. New Delhi; 31 May 2021. Available from: http://covidtracker.tnaionline.org/ [Last accessed on 2021 May 31].

6. World health organization. Ten threats to global health in 2019. Geneva: WHO. Available from: https://www.who.int/newsroom/spotlight/ten-threats-to-global-healthin-2019 [Last accessed on 2021 July 19].

7. World health organization. National heath workforce accounts data portal. Geneva: WHO. 2020. Available from: https://apps.who.int/nhwaportal/Sown/Files? name $=$ IND [Last accessed on 2021 Aug 11].

8. Voysey M, Clemens SAC, Madhi SA, Weckx LY, Folegatti PM, Aley PK, et al. Safety and efficacy of the ChAdOx1 nCoV19 vaccine (AZD1222) against SARS-CoV2: an interim analysis of four randomised controlled trials in Brazil, South Africa, and the UK. The Lancet 2021; 397(10269): 99111

9. Fakonti, Georgia, Kyprianidou, Maria, Toumbis, Giannos, et al. Attitudes and acceptance of COVID-19 vaccination among nurses and midwives in Cyprus: A cross-sectional survey. Frontiers in Public Health 2021; 9: 1-10

10. Abdel Wahed WY, Hefzy EM, Ahmed MI, Hamed NS. Assessment of knowledge, attitudes, and perception of health care workers regarding COVID-19, a crosssectional study from Egypt. J Community Health 2020; 45(6):1242-51

11. Batra V, Goswami A, Dadhich S, Kothari D, Bhargava N. Hepatitis B immunization in healthcare workers. Annals of gastroenterology 2015;28(2): 276-80

12. Fazili Anjum B, Iqbal Qazi M, Mushtaq B, Shah Rohul J, Ganai Abdul M. Study on hepatitis $\mathrm{B}$ vaccination coverage among workforce of a tertiary care hospital in North India. International Journal of Medical Research \& Health Sciences 2016; 5( 5):115-20

13. Pathak R, Chaudhary C, Pathania D, Ahluwalia SK, Prabhakar K. Mishra, and Kahlon AS. Hepatitis B Vaccine: Coverage and Factors Relating to its Acceptance among Health Care Workers of a Tertiary Care Center in North India. International Journal of Medicine and Public Health 2013; 3(1):55-59

14. Press information bureau. Bleeding and clotting events following COVID vaccination miniscule in India 2021. New Delhi: Ministry of health and family welfare, Government of India. Available from:https://pib.gov.in/PressReleasePage.as px?PRID $=1719293$ [Last accessed on 2021 Aug 18].

How to cite this article: Jadhav ST, Gurung K. COVID-19 vaccination - a cross sectional survey on attitude and belief of nurses. International Journal of Science \& Healthcare Research. 2022; 7(1): 135-139. DOI: https:// doi.org/10.52403/ijshr.20220123 